\title{
Questionários sistemáticos e smartphone: ferramentas de avaliação pedagógica?
}

\author{
Carlos Seco, Teresa Cardoso \\ LE@D - Laboratório de Educação a Distância e Elearning, Universidade Aberta (Portugal)
}

\begin{abstract}
Resumo
Este estudo pretende dar resposta à questão de como os questionários sistemáticos e os smartphones podem ajudar o professor na sua tarefa de avaliação pedagógica das suas práticas. O estudo incidiu em três turmas, num universo de 49 alunos. Os alunos inquiridos foram respondendo a um questionário no final de cada aula no smartphone e os resultados foram depois sujeitos a uma análise estatística. Como conclusão, constata-se que os questionários sistemáticos permitem analisar o modo como os alunos acompanharam cada aula, permitindo ao professor ir ao encontro das suas expectativas e motivações.

Palavras-chave: avaliação pedagógica, questionários sistemáticos, smartphone.
\end{abstract}

\section{Introdução}

A questão da avaliação pedagógica é sem dúvida um tema sempre atual e sobre o qual muitos investigadores já escreveram. É relativamente fácil encontrarmos literatura especializada e de referência sobre a questão da avaliação pedagógica dos alunos. O mesmo já não se passa em relação aos professores, o que é sem dúvida extremamente importante, pois a avaliação deve ajudar-nos a conhecer e a compreender a realidade para que se possa transformar e melhorar (Fernandes, 2009: 20). E, são os professores que tem um peso fundamental no processo de aprendizagem dos alunos (conforme a sua atitude em cada aula). Então como podemos avaliar as nossas próprias práticas?

Ao longo dos anos, muitas formas foram utilizadas, desde o recurso a colegas observadores a questionários aos alunos. Recentemente, com o avanço tecnológico é possível recorrer a computadores e a software de construção de questionários online de fácil acesso por parte dos alunos. Mas sabemos que em muitas escolas e em muitas salas de aulas os alunos não tem à sua disposição computadores, então, como fazê-lo nesta situação? A resposta será quase imediata, pois sabemos, enquanto professores, que o smartphone é o dispositivo eletrónico que praticamente todos os nossos alunos possuem e usam.

\section{Enquadramento teórico}

A avaliação é, como nos diz Fernandes (2009), um domínio científico e uma prática social cada vez mais indispensável para caracterizar, compreender, divulgar e melhorar uma grande variedade de problemas que afetam as sociedades contemporâneas, tais como a qualidade da educação e do ensino, a prestação de cuidados de saúde, a distribuição de recursos e a pobreza. É portanto imperativo que o professor possa ser avaliado e conhecer os seus pontos fracos e fortes, instituindo, dessa forma, "uma lógica de criticidade que expõe consistências e contradições às práticas, validando-as ou sujeitando-as a novas formulações, e evitando a sua fossilização" (Fernandes e Vieira, 2010:279).

A avaliação pode ter também um carater de (auto) supervisão, de natureza intrapessoal, pois o professor reflexivo, disposto a um desenvolvimento profissional contínuo, ganha relevo na medida em que se torna capaz de se assumir como supervisor das suas próprias práticas (Alarcão \& Roldão, 2008).

Podemos, como antes aludimos, recorrer a diversos métodos de avaliação, tais como, por exemplo: aulas assistidas por colegas; questionários focados em pontos críticos de avaliação; grelhas de avaliação; ou mesmo recorrendo a tecnologias como por exemplo a gravação das aulas para visionamento posterior. No entanto, hoje em dia com as novas tecnologias os professores tendem a aproximação com os alunos através do uso dos computadores, tablets e sobretudo através dos dispositivos que praticamente todos os alunos trazem consigo, os smartphones. Como nos diz Rogers e Wright (2008), estas tecnologias abrem novos meios de suporte à comunicação entre professores, pais e alunos.

Por outro lado, os alunos hoje em dia interagem com os smartphones com a destreza de nativos digitais o que permite ao professor chegar mais perto e interagir dentro do mesmo meio dos seus alunos. Expressões como “Sociedade das Comunicações Móveis” (Castells, 2004), "Cultura do Telemóvel” (Goggin, 2006), "Thumb Culture” (Glotz et al., 2005), "Mobile Age” (Sharples et al., 2005) significam que as tecnologias móveis estão cada vez mais enraizadas na nossa sociedade fazendo parte do dia-a-dia dos nossos alunos, alterando o paradigma e os hábitos de todos nós, na forma como trabalhamos, ensinamos e aprendemos.

\section{Caraterização geral do estudo}

\section{Questões de investigação}

Estudos sobre a utilização dos smartphones na sala de aula apontam para uma ausência de decisões por parte da escola sobre uma política do uso do telemóvel (Twiss, 2009) e nos casos em que existe, a maioria, é no sentido da proibição do uso do smartphone em sala de aula. No entanto, e segundo o relatório do primeiro trimestre de 2015 da ANACOM (Autoridade Nacional de Comunicações), a penetração do serviço móvel em Portugal com utilização efetiva era de 122,6 por 100 habitantes. 
Se temos disponível esta ferramenta e se os nossos alunos lidam com ela com destreza, será então que podemos utilizar o smartphone como uma ferramenta de suporte aos questionários sistemáticos para fazer a avaliação pedagógica do próprio professor? Esta é a questão de investigação que iremos responder neste estudo.

\section{Objetivos da investigação}

Este estudo tem como objetivo não só responder à pergunta de investigação acima elencada como também observar o comportamento dos alunos face ao uso do smartphone em sala de aula. No final de cada aula, o professor pediu a colaboração dos seus alunos para responderem a um questionário pré-construído, ao qual os alunos tinham acesso nos seus smartphones. As respostas foram automaticamente transformadas em gráficos e analisadas em tempo real, permitindo assim ao professor saber quais os seus pontos fortes e fracos no decorrer da aula.

\section{Recursos tecnológicos utilizados}

\section{gis socrative}

Figura 1. Logotipo do software socrative. http://www.socrative.com/

Foi utilizado o "socrative" (cf. figura 1), aplicação que, entre outras funcionalidades, permite ao professor criar os questionários e ver as estatísticas geradas pelas respostas dos alunos em tempo real.

O socrative funciona com duas versões que podem ser instaladas no smartphone, uma na versão do professor e outra na versão de aluno (figura 2), cada uma delas corre nos sistemas Android, iOS e Chrome da Google.

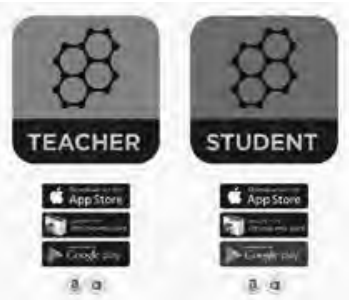

Figura 2. As duas versões do socrative. http://www.socrative.com/apps.php

O professor criar uma sala virtual no software e dá início ao questionário (figura 3).

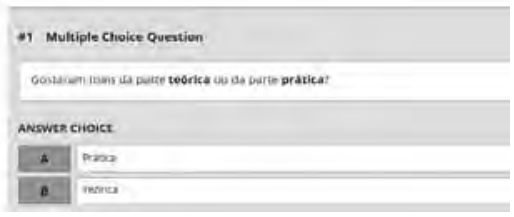

Figura 3. Exemplo de uma pergunta.
Os alunos ao entrarem na sua versão colocam o nome da sala virtual, fornecido pelo professor, ficando com acesso ao questionário e iniciam o processo de respostas (figura 4).

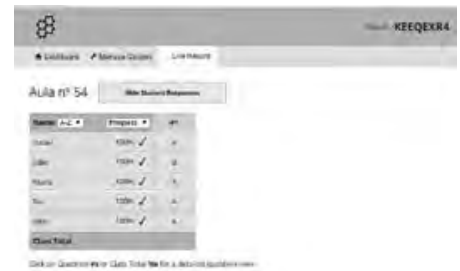

Figura 4. Respostas de todos os alunos.

O software cria em tempo real um gráfico com as respostas e percentagens dadas pelos alunos (figura 5).

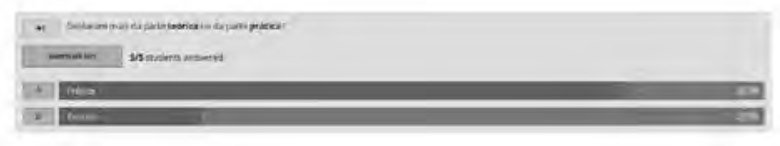

Figura 5. Gráfico gerado com as percentagens para uma resposta.

Com base neste gráfico, o professor analisa as respostas e chega à conclusão, por exemplo, que os alunos gostaram muito mais das aulas práticas do que das aulas teóricas.

O software socrative permite, para além dos questionários, a construção de testes, ou mesmo saber as respostas da turma instantaneamente a uma pergunta que o professor faça na aula, e ainda permite a construção de relatórios com estatísticas completas que podem ser exportadas e trabalhadas no Excel.

\section{Importância do estudo}

Este estudo tem duas componentes, uma tecnológica e outra pedagógica. A tecnológica tem que ver com o uso do smartphone, como nos disse um aluno ele é mais fácil de usar do que um caderno, leva mais coisas, é mais rápido, mais fácil de transportar, leva todas as disciplinas e mais a internet quando é preciso. Como nos diz Moura (2010), a tecnologia é útil quando se adequa às necessidades diárias de comunicação, de trabalho e de aprendizagem, estando assim também presente a sua parte pedagógica como ferramenta de aprendizagem nos nossos dias. Os alunos trabalham de maneira diferente com os dispositivos móveis, porque estes se tornaram pessoais e íntimos (Alexander, 2004).

Este estudo é importante pois permite juntar a tecnologia e a pedagogia, para que o professor de uma forma rápida e eficiente possa avaliar a sua prática e responder de imediato melhorando a sua forma de estar na sala de aula, indo ao encontro das expetativas dos seus alunos. É, pois, um estudo inovador e importante do ponto de vista da avaliação dos professores. 


\section{Metodologia}

\section{Fundamentos metodológicos}

Segundo Gil (2007, p. 17), pesquisa é definida como “o (...) procedimento racional e sistemático que tem como objetivo proporcionar respostas aos problemas que são propostos. A pesquisa desenvolve-se por um processo constituído de várias fases, desde a formulação do problema até a apresentação e discussão dos resultados”.

Neste estudo recorreu-se a uma metodologia qualitativa, tendo em conta que, segundo Duarte (2002, p. 140), “a definição do objeto de pesquisa assim como a opção metodológica constituem um processo tão importante para o pesquisador, quanto o texto que se elabora no final".

A metodologia qualitativa, como nos diz Dantas \& Calvacante (2006), tem caráter exploratório, isto é, estimula os entrevistados a pensarem livremente sobre algum tema, objeto ou conceito, mostrando aspetos subjetivos e atingem motivações não explícitas, ou mesmo conscientes, de maneira espontânea. É utilizada quando se pretende compreender perceções e obter entendimento sobre a natureza geral de uma questão, abrindo espaço para a interpretação. O investigador desenvolve conceitos, ideias e entendimentos a partir de padrões encontrados nos dados, em vez de recolher dados para comprovar teorias, hipóteses e modelos pré-concebidos.

A investigação realizada é uma investigação qualitativa em educação, complementada por dados quantitativos. As estratégias de recolha de dados utilizadas foram a observação direta e participante e os inquéritos através de questionários eletrónicos com questões abertas e fechadas, além de respostas de múltipla escolha, que segundo Tuckman (2002) é muito utilizado no campo educativo.

\section{Participantes do estudo}

A população participante foram 46 alunos de três turmas (uma do $12^{\circ}$ ano do Ensino Secundário, outra do Curso Vocacional do $9^{\circ}$ ano e a outra, do Curso de Educação e Formação do $9^{\circ}$ ano), de uma escola portuguesa - alunos com idades compreendidas entre os 15 e 18 anos, sendo 36 do sexo masculino e 10 do sexo feminino.

\section{Instrumentos de recolha de dados}

A recolha de dados foi feita através da própria aplicação socrative online em tempo real, no smartphone dos alunos.

Os alunos respondem a uma pergunta, a aplicação passa para a próxima até à conclusão do questionário e o professor, na sua aplicação (no smartphone ou no computador), vai controlando a quantidade de respostas dadas em cada momento.

No final, o professor obtém da aplicação um gráfico demonstrativo em percentagem das respostas de todos os alunos às perguntas.

\section{Tratamento e análise de dados}

Os dados foram divididos por turma e por aula, para que se poder obter um resultado fiel por aula lecionada. Assim, pelos dados obtidos, é possível saber os interesses manifestados pelos alunos e direcionar as próximas aulas para questões com que os alunos se identificaram.

A recolha de dados foi feita de forma anónima para não constranger os alunos nas suas respostas.

Posteriormente as respostas dos alunos aos questionários foram exportados diretamente do socrative para o Excel, para se poder ter uma visão geral do perfil destes alunos mediante o padrão de aula dado. Foram analisadas perguntas de carater geral como exemplo:

Gostou mais da parte prática?

Gostou mais da parte teórica?

Gostou mais de trabalhar em equipa?

Gostou mais de trabalhar sozinho?

Gostou mais da explicação do professor?

Gostou mais de ver o vídeo?

Achou a explicação difícil?

Achou a explicação fácil?

A partir das respostas às questões, foi possível construir gráficos como o representado na figura 6.

As perguntas foram sendo repetidas com algumas alterações específicas de cada aula, ao longo de um mês.

Foi possível construir um padrão nas respostas como por exemplo, se gosta mais da aula práticas ou das aulas teóricas, em que se conseguiu observar que independentemente da aula em questão, a preferência pelas aulas práticas sempre superaram o gosto pelas aulas teóricas, o mesmo podemos observar nas respostas à questão sobre se gosta mais de trabalhar em equipa ou sozinho, em que o padrão obtido no conjunto das aulas é o de que os alunos preferem trabalhar em equipa. $\mathrm{O}$ gráfico da figura 6 mostra o comportamento padrão dos alunos ao longo das aulas em que responderam aos questionários.

Podemos observar que os alunos no geral também preferem a explicação do professor em vez de assistir a vídeos e que consideram que o professor tem uma linguagem de fácil compreensão.

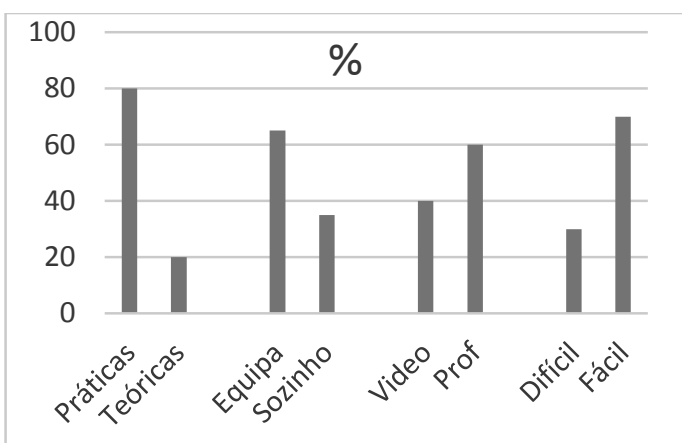

Figura 6. Gráfico representativo de alguns resultados padrão obtidos

Também foram feitas perguntas específicas para cada aula, como antes mencionado. Neste caso, as respostas dadas pelos alunos foram analisadas tendo em conta que podem permitir ao professor entender e melhorar a sua 
prática pedagógica e a contextualização desse item numa futura aula em que se repitam as mesmas condições.

\section{Considerações finais}

A reação por parte dos alunos ao uso dos seus próprios smartphones foi muito positiva e motivou bastante a interação entre os alunos e o professor. Exemplo disso foi o verdadeiro interesse por parte dos alunos pela novidade do uso dos seus smartphones, havendo mesmo perguntas como por exemplo: "podemos usar os smartphones nas respostas aos testes?” ou ainda, "porque os professores não permitem mais o uso dos smartphones na sala de aula?”. Ou afirmações, como a que se transcreve e que demonstra como a inovação pode ser motivadora para os alunos: "se fosse sempre assim, eu nunca faltava às aulas!".

Desta forma, o smartphone para além de poder ser usado como ferramenta de avaliação pedagógica das práticas docentes, mediante questionários sistemáticos, pode ser uma ferramenta interativa na sala de aula. Por outro lado, constatou-se que motiva o interesse por parte dos alunos na sala de aula sendo ainda uma ferramenta mediadora de aprendizagem, permitindo aumentar a motivação dos alunos.

\section{Conclusões}

Depois de decorrido este processo resta analisar os dados e responder às questões de investigação, assim as conclusões do estudo são possíveis devido aos instrumentos utilizados na recolha de dados e a interpretação dos resultados obtidos, sendo que a descrição desses procedimentos, além de apresentar uma formalidade, permite a outros autores percorrerem o mesmo caminho da pesquisa e confirmarem as afirmações apontadas no estudo inicial.

O conceito desta investigação é tanto mais válida quanto melhor as perguntas dos questionários estiverem elaboradas e de acordo com as temáticas a investigar.

De uma forma geral e de acordo com a figura 6 observamos que os alunos preferem as aulas prática às teóricas (80\% contra 20\%), preferem trabalhar em equipa do que sozinhos (65\% contra $35 \%)$, preferem a explicação do professor em vez de assistirem a vídeos (60\% contra $40 \%$ ) e $70 \%$ acha que a explicação do professor é de fácil entendimento (contra 30 \% que acha de difícil compreensão).

Com estes resultados o professor pode retirar de imediato algumas conclusões, como por exemplo continuar a preferir as aulas práticas com trabalho em equipa, acompanhando os alunos nos seus projetos, indo supervisionando, explicando e orientando as suas atividades ao longo da aula.

Desta forma, o professor tem um retorno imediato e pode fazer a sua avaliação no fim de cada aula, redirecionando o seu comportamento para as próximas.

Isto só se torna possível com a aplicação do socrative, ou similar, o que comprova que podemos então considerar que os questionários sistemáticos com recurso ao smartphone pode na realidade ser usado como uma ferramenta de avaliação pedagógica.

\section{Referências}

Alarcão, I. e Roldão, M. C. (2008). Supervisão: um Contexto de Desenvolvimento Profissional dos Professores. Mangualde: Pedago.

Alexander, B. (2004). Going Nomadic: Mobile Learning in Higher Education. EDUCAUSE Review, 39(5), 2835. Disponível em http://www.educause.edu/ir/library/pdf/erm0451.p df/ e acedido em 13 de junho de 2015.

ANACOM (Autoridade Nacional de Comunicações) Serviços Móveis Informação Estatística $1^{\circ}$ Trimestre de 2015. Disponível em http://www.anacom.pt/streaming/SM_1T2015.pdf?co ntentId=1356833\&field=ATTACHED_FILE e acedido em 12 de junho de 2015.

Castells, M. (2004). A Galáxia Internet: Reflexões sobre Internet, Negócios e Sociedade. Lisboa: Fundação Calouste Gulbenkian.

Dantas M. \& Cavalcante V. (2006) Pesquisa Qualitativa e Pesquisa Quantitativa. Universidade Federal de Pernambuco de Artes e Comunicação Ciência da Informação.

Duarte, R. (2002) Pesquisa qualitativa: reflexões sobre o trabalho de campo. Caderno de Pesquisa, $n^{\circ} 115$, p. 139-154.

Fernandes, D. (2009). Avaliação do Desempenho Docente: Desafios, Problemas e Oportunidades.

Fernandes, D. (2009). Para uma avaliação de professores com sentido social e cultural. ELO 16 - Avaliação do Desempenho Docente, Maio, pp. 19-23.

Fernandes, I.S. e Vieira, F. (2010). A supervisão como um jogo de subversão de regras. In F. Vieira, M.A.Moreira. I. Barbosa, M. Paiva e I.S. Fernandes (autoras). No caleidoscópio da supervisão: Imagens da formação e da pedagogia. Mangualde: Edições Pedago, pp. 275-280.

Gil, A. C. Como elaborar projetos de pesquisa. 4. ed. São Paulo: Atlas, 2007.

Glotz, P. Bertsch, S., \& Locke, C. (2005). Thumb Culture: The Meaning of Mobile Phones for Society. Bielefelt: Verlag.

Goggin, G. (2006). Cell Phone Culture: Mobile Technology in Everyday Life. New York: Routledge.

Moura A. (2010) Apropriação do Telemóvel como Ferramenta de Mediação em Mobile Learning: Estudos de Caso em Contexto Educativo. Tese Doutoral, Instituto de Educação, Universidade do Minho, Braga, Portugal. Disponível em http://repositorium.sdum.uminho.pt/bitstream/1822/13 183/1/Tese\%20Integral.pdf e acedido em 12 de junho 2015.

Rogers, R. R. H., \& Wright, V. H. (2008). Assessing technology's role in communication between parents and middle schools. Electronic Journal for the Integration of Technology in Education, 7, 36-58.

Sharples, M., Corlett, D., Bull, S., Chan, T., \& Rudman, P. (2005). The Student Learning Organiser. In A. Kukulska-Hulme, \& J. Traxler (eds.) Mobile Learning: 
A Handbook for Educators and Trainers (pp. 139-149). London: Routledge.

Tuckman, B. (2002). Manual de investigação em educação: como conceber e realizar o processo de investigação em educação. Lisboa: Fundação Calouste Gulbenkian.

Twiss, T. (2009). Mobile Phones in the Classroom - A Review of Literature. Disponível em http://www.mobileactive.org/research/mobile-phonesclassroom-review-literature e acedido em 12 de junho 2015.

\section{Agradecimentos}

Agradeço a todos os meus alunos que contribuíram com as suas respostas a estes questionários, durante várias aulas, ajudando-me assim, não só a melhorar as minhas práticas, como também contribuíram com os dados, para que fosse possível avançar e concluir esta investigação.

Carlos Seco 